\title{
Incidence and Outcomes of Hemorrhagic Stroke among Adults in Spain (2016-2018) According to Sex: A Retrospective, Cohort, Observational, Propensity Score Matched Study
}

\author{
Jose M. de Miguel-Yanes ${ }^{1}\left(\mathbb{D}\right.$, Ana Lopez-de-Andres ${ }^{2}, *\left(\mathbb{0}\right.$, Rodrigo Jimenez-Garcia ${ }^{2}(\mathbb{D}$, \\ Valentin Hernandez-Barrera ${ }^{3}$, Javier de Miguel-Diez ${ }^{4}\left(\mathbb{C}\right.$, Manuel Méndez-Bailón ${ }^{5}$, Napoleón Pérez-Farinós ${ }^{6}(\mathbb{D}$, \\ Nuria Muñoz-Rivas ${ }^{7}$, David Carabantes-Alarcon ${ }^{2}$ [D and Marta López-Herranz ${ }^{8}$
}

check for

updates

Citation: de Miguel-Yanes, J.M.; Lopez-de-Andres, A.; Jimenez-Garcia,

R.; Hernandez-Barrera, V.; de

Miguel-Diez, J.; Méndez-Bailón, M.; Pérez-Farinós, N.; Muñoz-Rivas, N. Carabantes-Alarcon, D.;

López-Herranz, M. Incidence and Outcomes of Hemorrhagic Stroke among Adults in Spain (2016-2018) According to Sex: A Retrospective, Cohort, Observational, Propensity Score Matched Study. J. Clin. Med. 2021, 10, 3753. https://doi.org/ $10.3390 /$ jcm10163753

Academic Editor: Aaron S. Dumon

Received: 9 July 2021

Accepted: 20 August 2021

Published: 23 August 2021

Publisher's Note: MDPI stays neutral with regard to jurisdictional claims in published maps and institutional affiliations.

Copyright: (c) 2021 by the authors. Licensee MDPI, Basel, Switzerland. This article is an open access article distributed under the terms and conditions of the Creative Commons Attribution (CC BY) license (https:// creativecommons.org/licenses/by/ $4.0 /)$.
1 Internal Medicine Department, Hospital General Universitario Gregorio Marañón, Instituto de Investigación Sanitaria Gregorio Marañón (IiSGM), Universidad Complutense de Madrid, 28040 Madrid, Spain; josemaria.demiguel@salud.madrid.org

2 Department of Public Health \& Maternal and Child Health, Faculty of Medicine, Universidad Complutense de Madrid, 28040 Madrid, Spain; rodrijim@ucm.es (R.J.-G.); dcaraban@ucm.es (D.C.-A.)

3 Preventive Medicine and Public Health Teaching and Research Unit, Health Sciences Faculty, Universidad Rey Juan Carlos, Alcorcón, 28922 Madrid, Spain; valentin.hernandez@urjc.es

4 Respiratory Department, Hospital General Universitario Gregorio Marañón, Instituto de Investigación Sanitaria Gregorio Marañón (IiSGM), Universidad Complutense de Madrid, 28040 Madrid, Spain; javier.miguel@salud.madrid.org

5 Internal Medicine Department, Hospital Universitario Clínico San Carlos, Universidad Complutense de Madrid, 28040 Madrid, Spain; manuel.mendez@salud.madrid.org

6 Public Health and Psychiatry Department, Faculty of Medicine, Universidad de Málaga, 29010 Málaga, Spain; napoleon.perez@uma.es

7 Internal Medicine Department, Hospital Universitario Infanta Leonor, 28031 Madrid, Spain; nmunozr@salud.madrid.org

8 Nursing Department, Faculty of Nursing, Physiotherapy and Podology, Universidad Complutense de Madrid, 28040 Madrid, Spain; martal11.ucm@gmail.com

* Correspondence: anailo04@ucm.es; Tel.: +34-91-394-1523

Abstract: (1) Background: We aim to analyze sex differences in the incidence, clinical characteristics and in-hospital outcomes of hemorrhagic stroke (HS) in Spain (2016-2018) using the National Hospital Discharge Database. (2) Methods: Retrospective, cohort, observational study. We estimated the incidence of HS in men and women. We analyzed comorbidity, treatments, procedures, and hospital outcomes. We matched each woman with a man by age, type of HS and medical conditions using propensity score matching. (3) Results: HS was coded in 57,227 patients aged $\geq 18$ years (44.3\% women). Overall, men showed higher incidence rates $\left(57.3 / 10^{5}\right.$ vs. $43.0 / 10^{5} ; p<0.001$; IRR $=1.60 ; 95 \%$ CI: $1.38-1.83)$. Women suffered more subarachnoid hemorrhages $(25.2 \%$ vs. $14.6 \%)$, whereas men more often had intracerebral hemorrhages (55.7\% vs. 54.1\%). In-hospital mortality (IHM) was higher for intracerebral hemorrhage in both men and women. Women underwent decompressive craniectomy less often than men $(5.0 \%$ vs. $6.2 \% ; p<0.001)$. After matching, IHM among women was higher $(29.0 \%$ vs. $23.7 \% ; p<0.001)$. Increments in age, comorbidity and use of anticoagulants and antiplatelet agents prior to hospitalization were associated were higher IHM, and decompressive craniectomy was associated with lower IHM in both sexes. After multivariable adjustment, women had higher IHM (OR = 1.23; 95\% CI: 1.18-1.28). (4) Conclusion: Men had higher incidence rates of HS than women. Women less often underwent decompressive craniectomy. IHM was higher among women admitted for HS than among men.

Keywords: hemorrhagic stroke; sex differences; decompressive craniectomy; in-hospital mortality 


\section{Introduction}

Hemorrhagic stroke (HS) is a devastating medical condition with a high short-term mortality. In a review published in 2010 , which included 36 population-based studies, the authors reported an incidence of 25 cases of HS per 100,000 inhabitants, with non-significant differences in the incidence between men and women [1]. However, other studies have generally found a higher overall incidence in men [2]. Most authors agree that incidence rates have remained relatively constant over time in developed countries [3], but they seem to have been growing in developing countries [4].

Very often, a distinction is not made between the subtypes of hemorrhagic stroke (e.g., intracerebral hemorrhage or subarachnoid hemorrhage), and some research exclusively evaluated cases of parenchymal bleeding. Subarachnoid hemorrhage is believed to be more common among women [5]. Therefore, lack of inclusion of all the subtypes of HS may yield apparently disparate numbers as far as incidence is concerned. Apart from the location of the bleeding, sex may influence the development of perihematomal edema, and treatment of the hemorrhagic stroke or its complications may differ according to sex [6,7].

In the review by van Asch et al., mortality during the first month after the event ranged from $16 \%$ to more than $50 \%$, with a median value around $40 \%$ [1]. Gokhale et al., underscored additional limitations of previous research work: many reports were from before 2000, some of the studies treated intracerebral hemorrhage as a stroke subtype in a total stroke population instead of considering it as a distinct entity, and relatively few studies included significant numbers of cases [8], albeit it is common to adjust for age and functional status [9]. Propensity score matching (PSM) is a method that makes populations with a different distribution of baseline variables associated with hospital outcomes more comparable and, therefore, reduces residual confounding [10].

Here we used PSM to assess the sex-related differences in the incidence, clinical characteristics, use of decompressive craniectomy and in-hospital mortality for patients admitted with a primary diagnosis of HS to Spanish hospitals from 2016 to 2018. We also used multivariable regression to identify which of the study variables were independently associated with in-hospital mortality (IHM) for women and men hospitalized with HS.

\section{Materials and Methods}

\subsection{Study Design and Data Source}

We conducted a retrospective observational cohort study based on the data collected by the Spanish National Hospital Discharge Database (SNHDD). This registry provides basic demographic data, up to twenty diagnoses and procedures, and the outcome for each hospitalization in any Spanish hospital. Since the year 2016, the International Classification of Disease version 10 (ICD-10) is being used for coding by the SNHDD. Detailed information on the SNHDD is available online [11].

\subsection{Study Population}

We analyzed data from adults (aged 18 years or over) registered by the SNHDD from 1 January 2016 to 31 December 2018. Only subjects discharged with a primary diagnosis of HS were included in the study population. The ICD-10 codes for HS are shown in Table S1. For study purposes, we grouped HS in three subtypes: "Nontraumatic subarachnoid hemorrhage", "Nontraumatic intracerebral hemorrhage" and "Other and unspecified nontraumatic intracranial hemorrhage".

As we do not have information on the characteristics of any previous stroke, all those patients with a code for history of previous stroke (ICD-10 code Z86.73) were excluded from the study population.

\subsection{Study Variables}

Our main study variables were the incidence of HS, the use of decompressive craniectomy and the IHM. Incidence rates were calculated using the Spanish populations by year, sex and age groups, provided by the Spanish National Statistics Institute as described 
before $[12,13]$. Patients were classified as receivers of a decompressive craniectomy if any of the codes for this procedure (Table S1) appeared in any of the 20 procedure fields. Secondary study variables included age, cardiovascular risk factors, alcohol abuse, comorbid conditions, the use prior to hospital admission of oral anticoagulants (OACs) and antiplatelet agents, receipt of mechanical ventilation (invasive and non-invasive) and length of hospital stay (LOHS). The codes for these conditions, treatments and procedures are shown in Table S1.

Comorbidity was assessed using the Charlson's comorbidity index (CCI) as categorized in three groups " $\mathrm{CCI}=0$ ", "CCI $=1$ " and " $\mathrm{CCI}>1$ ". The ICD-10 codes to identify the CCI conditions were those described by Sundararajan et al. [14]. Additional variables accounted for were atrial fibrillation, anemia, depression, sepsis and nosocomial pneumonia (ICD-10 codes shown in Table S1).

\subsection{Matching Method}

PSM analysis was applied to control for the confounding effect of sex differences in the baseline characteristics that can be associated with our main study variables. The PSM model was constructed including type of HS (up to the last two decimals), age, cardiovascular risk factors and other conditions present on admission. Details regarding the PSM approach with the SNHDD have been described elsewhere [15].

\subsection{Statistical Analysis}

All results are presented separately for women and men. To estimate differences in the incidences according to sex and age groups, we constructed age-adjusted Poisson regression models.

We report means with standard deviation (SD), or medians with interquartile range (IQR) for age/CCI and LOHS, respectively. For all the remaining variables, absolute frequencies and percentages are shown.

Mean values between men and women were compared using the t-test, or the MannWhitney test, depending on the homogeneity of the variance (Levene's test). Differences in percentages were assessed using the chi-square test. We constructed multivariable logistic regression models to identify the variables associated with IHM among men and women. Details on model construction have been provided elsewhere [15].

\subsection{Sensitivity Analysis}

To confirm the results of the PSM to assess the sex-related differences in the IHM, we complemented the statistical analysis creating multivariable logistic regression models including the entire study population and considering sex as the main outcome variable.

The PSM process and all bivariate and multivariable analyses were conducted using Stata version 14 (Stata, College Station, TX, USA). For all comparisons, statistical significance was set at a $p$ value $<0.05$ (two-sided).

\subsection{Ethical Aspects}

This study was conducted using secondary administrative data that can be obtained on request to the Spanish health authorities by any investigator [16]. All personal identifiers were deleted before the databases were provided to us, so confidentiality was fully ensured. Therefore, and according to the Spanish laws, it is unnecessary to present the study protocol for evaluation to an ethics committee.

\section{Results}

From 2016 to 2018 , a total of 57,227 patients aged $\geq 18$ years were discharged from Spanish hospitals with a primary diagnosis of HS. Men accounted for $55.7 \%(n=31,868)$ and women for $44.3 \%(n=25,359)$. 


\subsection{Incidence of Hemorrhagic Stroke According to Sex}

The global incidence of HS per 100,000 inhabitants was higher among men $\left(57.3 / 10^{5}\right)$ than among women $\left(43.0 / 10^{5} ; p<0.001\right)$ (Table 1$)$, and differences in the same direction were seen in all age strata. For both sexes, incidences increased with age, reaching the highest values in people 85 years old or over $\left(346.3 / 10^{5}\right.$ and $213.0 / 10^{5}$ in men and women, respectively). Using age-adjusted Poisson regression analyses, we obtained an incidence rate ratio (IRR) of 1.60 (95\% confidence interval (CI): 1.38-1.83). This means that in the period 2016/2018 men had a 60\% greater incidence of hospitalizations for HS than women did.

Table 1. Incidence of hospitalizations for hemorrhagic stroke in Spain from 2016 to 2018 according to sex and age groups.

\begin{tabular}{|c|c|c|c|}
\hline & Women & Men & \\
\hline Age Groups & $n$ (Inc/10 5 Women) & $n\left(\right.$ Inc/10 $10^{5}$ Men $)$ & $p$-Value \\
\hline $18-54$ years & 3787 (10.8) & 5134 (14.5) & $<0.001$ \\
\hline 55-69 years & 4948 (38.9) & $8256(68.8)$ & $<0.001$ \\
\hline $70-84$ years & $10,540(123.7)$ & $13,469(201.8)$ & $<0.001$ \\
\hline$\geq 85$ years & $6084(213.0)$ & $5009(346.3)$ & $<0.001$ \\
\hline All age groups & $25,359(43.0)$ & $31,868(57.3)$ & $<0.001$ \\
\hline
\end{tabular}

Inc $/ 10^{5}$ : Incidence per 100,000 inhabitants. The $p$-values are for comparisons between men and women.

\subsection{Clinical Characteristics and Hospital Outcomes According to Sex}

The distribution according to type of HS, age, CCI, cardiovascular risk factors, lifestyle variables and use of OACs and antiplatelet agents before and after PSM for men and women are shown in Table 2. Mean ages were 72.7 years old for women and 70.2 years for men $(p<0.001)$. Men were overrepresented in the younger age groups and women in the older ones.

Table 2. Type of hemorrhagic stroke, age, Charlson comorbidity index, cardiovascular risk factors and alcohol abuse before and after propensity score matching (PSM) for men and women hospitalized for hemorrhagic stroke in Spain from 2016 to 2018 .

\begin{tabular}{|c|c|c|c|c|c|c|}
\hline \multirow{2}{*}{ Variables } & \multicolumn{3}{|c|}{ Before PSM } & \multicolumn{3}{|c|}{ After PSM } \\
\hline & Women & Men & $p$-Value & Women & Men & $p$-Value \\
\hline $\begin{array}{c}\text { Nontraumatic subarachnoid } \\
\text { hemorrhage, } n(\%)\end{array}$ & $6382(25.2)$ & $4642(14.6)$ & $<0.001$ & $6382(25.2)$ & $4422(17.44)$ & $<0.001$ \\
\hline $\begin{array}{c}\text { Nontraumatic intracerebral } \\
\text { hemorrhage, } n(\%)\end{array}$ & $13,730(54.1)$ & $17,759(55.7)$ & $<0.001$ & $13,730(54.1)$ & $14,326(56.5)$ & $<0.001$ \\
\hline $\begin{array}{l}\text { Other and unspecified nontraumatic } \\
\text { intracranial hemorrhage, } n(\%)\end{array}$ & 5247 (20.7) & 9467 (29.7) & $<0.001$ & 5247 (20.7) & $6611(26.1)$ & $<0.001$ \\
\hline Age, mean (SD) & $72.74(15.1)$ & $70.20(14.4)$ & $<0.001$ & $72.74(15.1)$ & $71.50(13.8)$ & $<0.001$ \\
\hline $18-54$ years, $n(\%)$ & 3787 (14.9) & $5134(16.1)$ & $<0.001$ & 3787 (14.9) & 3523 (13.9) & $<0.001$ \\
\hline 55-69 years, $n(\%)$ & 4948 (19.5) & $8256(25.9)$ & $<0.001$ & 4948 (19.5) & $6291(24.8)$ & $<0.001$ \\
\hline $70-84$ years, $n(\%)$ & $10,540(41.6)$ & $13,469(42.3)$ & 0.091 & $10,540(41.6)$ & $11,063(43.6)$ & $<0.001$ \\
\hline$\geq 85$ years, $n(\%)$ & $6084(24.0)$ & $5009(15.7)$ & $<0.001$ & $6084(24.0)$ & $4482(17.7)$ & $<0.001$ \\
\hline CCI, mean (SD) & $0.67(0.7)$ & $0.85(0.76)$ & $<0.001$ & $0.67(0.7)$ & $0.63(0.6)$ & $<0.001$ \\
\hline $\mathrm{CCI}=0, n(\%)$ & $13,316(52.5)$ & $14,202(44.6)$ & $<0.001$ & $13,316(52.5)$ & $13,449(53.0)$ & 0.237 \\
\hline $\mathrm{CCI}=1, n(\%)$ & $8224(32.4)$ & $10,856(34.1)$ & $<0.001$ & $8224(32.4)$ & $8600(33.9)$ & $<0.001$ \\
\hline $\mathrm{CCI}>1, n(\%)$ & $3819(15.1)$ & $6810(21.4)$ & $<0.001$ & $3819(15.1)$ & $3310(13.1)$ & $<0.001$ \\
\hline Obesity, $n(\%)$ & $1377(5.4)$ & $1631(5.1)$ & 0.097 & $1377(5.4)$ & $1159(4.6)$ & $<0.001$ \\
\hline Hypertension, $n$ (\%) & $13,134(51.8)$ & $17,045(53.5)$ & $<0.001$ & $13,134(51.8)$ & $13,548(53.4)$ & $<0.001$ \\
\hline Lipid metabolism disorders, $n(\%)$ & $7374(29.1)$ & $9453(29.7)$ & 0.127 & $7374(29.1)$ & $7092(28.0)$ & 0.006 \\
\hline Alcohol abuse, $n(\%)$ & $411(1.6)$ & $2971(9.3)$ & $<0.001$ & $411(1.6)$ & $1982(7.8)$ & $<0.001$ \\
\hline Use of oral anticoagulants, $n(\%)$ & $3478(13.71)$ & $4404(13.82)$ & 0.718 & $3478(13.71)$ & $3467(13.67)$ & 0.887 \\
\hline Use of antiplatelet agents, $n(\%)$ & $1983(7.82)$ & $3211(10.08)$ & $<0.001$ & $1983(7.82)$ & $2002(7.89)$ & 0.754 \\
\hline
\end{tabular}

PSM: propensity score matching. SD: standard deviation. CCI: Charlson comorbidity index. The $p$-values are for comparisons between men and women. 
We found significant sex differences for the type of HS. Women suffered more subarachnoid hemorrhages (25.2\% vs. $14.6 \%$ ), whereas men were more often admitted for intracerebral hemorrhages (55.7\% vs. $54.1 \%$ ) and unspecified intracranial hemorrhages $(29.7 \%$ vs. $20.7 \%$ ) (all $p$-values $<0.001)$. The mean number of comorbidities, according to the CCI, was higher among men than among women $(0.85$ vs. $0.67 ; p<0.001)$. Men had a code for hypertension and for alcohol abuse more frequently than women did.

The use of OACs $(13.71 \%$ vs. $13.82 \% ; p=0.718)$ was similar in both sexes whereas use of antiplatelet agents was significantly more prevalent among men $(10.08 \%$ vs. $7.82 \%$; $p<0.001)$.

Men suffered most comorbid conditions analyzed with a significantly higher prevalence than women, exceptions made for dementia, rheumatoid disease, anemia and depression, which were more prevalent among women (Table 3). Women underwent decompressive craniectomy less often than men did: $5.0 \%$ vs. $6.4 \%$ before PSM $(p<0.001)$, and $5.0 \%$ vs. $6.2 \%$ after PSM $(p<0.001)$. LOHS and IHM showed significantly worse figures for women than for men. After PSM, IHM among women admitted for a HS was over 5 points higher than among men $(29.0 \%$ vs. $23.7 \% ; p<0.001)$.

Table 3. Comorbidities, use of therapeutic procedures and hospital outcomes before and after propensity score matching (PSM) for men and women hospitalized for hemorrhagic stroke in Spain from 2016 to 2018.

\begin{tabular}{|c|c|c|c|c|c|c|}
\hline \multirow{2}{*}{ Variables } & \multicolumn{3}{|c|}{ Before PSM } & \multicolumn{3}{|c|}{ After PSM } \\
\hline & Women & Men & $p$-Value & Women & Men & $p$-Value \\
\hline Acute myocardial infarction, $n(\%)$ & $320(1.3)$ & $1085(3.4)$ & $<0.001$ & $320(1.3)$ & $144(0.6)$ & $<0.001$ \\
\hline Congestive heart failure, $n(\%)$ & $1020(4.0)$ & $1237(3.9)$ & 0.391 & $1020(4.0)$ & $922(3.6)$ & 0.023 \\
\hline Peripheral vascular disease, $n(\%)$ & $399(1.6)$ & $1230(3.9)$ & $<0.001$ & $399(1.6)$ & $225(0.9)$ & $<0.001$ \\
\hline Dementia, $n(\%)$ & $1916(7.6)$ & $1390(4.4)$ & $<0.001$ & $1916(7.6)$ & $1314(5.2)$ & $<0.001$ \\
\hline COPD, $n(\%)$ & $1340(5.3)$ & $3016(9.5)$ & $<0.001$ & $1340(5.3)$ & $1198(4.7)$ & 0.004 \\
\hline Rheumatoid disease, $n(\%)$ & $408(1.6)$ & $232(0.7)$ & $<0.001$ & $408(1.6)$ & $229(0.9)$ & $<0.001$ \\
\hline Peptic ulcer, $n(\%)$ & $55(0.2)$ & $138(0.4)$ & $<0.001$ & $55(0.2)$ & $49(0.2)$ & 0.556 \\
\hline Diabetes, $n(\%)$ & $4475(17.7)$ & $7449(23.4)$ & $<0.001$ & 4475 (17.7) & $4884(19.3)$ & $<0.001$ \\
\hline Hemiplegia/Paraplegia, $n(\%)$ & $4009(15.8)$ & $5474(17.2)$ & $<0.001$ & $4009(15.8)$ & $4097(16.2)$ & 0.286 \\
\hline Chronic renal disease, $n(\%)$ & $1615(6.4)$ & $2619(8.2)$ & $<0.001$ & $1615(6.4)$ & $1612(6.4)$ & 0.956 \\
\hline Chronic liver disease, $n(\%)$ & $777(3.1)$ & $1670(5.2)$ & $<0.001$ & $777(3.1)$ & $778(3.1)$ & 0.979 \\
\hline Cancer, $n(\%)$ & $440(1.7)$ & $1113(3.5)$ & $<0.001$ & $440(1.7)$ & $344(1.4)$ & 0.001 \\
\hline Metastatic cancer, $n(\%)$ & $251(1.0)$ & $448(1.4)$ & $<0.001$ & $251(1.0)$ & $269(1.1)$ & 0.428 \\
\hline AIDS, $n(\%)$ & $21(0.9)$ & $94(0.3)$ & $<0.001$ & $21(0.9)$ & $5(0.0)$ & 0.002 \\
\hline Atrial fibrillation, $n(\%)$ & $4644(18.3)$ & $5715(17.9)$ & 0.241 & $4644(18.3)$ & $4533(17.9)$ & 0.200 \\
\hline Anemia, $n(\%)$ & $726(2.9)$ & $626(2.0)$ & $<0.001$ & $726(2.9)$ & $563(2.2)$ & $<0.001$ \\
\hline Depression, $n(\%)$ & $1928(7.6)$ & $960(3.0)$ & $<0.001$ & $1928(7.6)$ & $938(3.7)$ & $<0.001$ \\
\hline Sepsis, $n(\%)$ & $254(1.0)$ & $462(1.5)$ & $<0.001$ & $254(1)$ & $355(1.4)$ & $<0.001$ \\
\hline Nosocomial pneumonia, $n(\%)$ & $421(1.7)$ & $684(2.2)$ & $<0.001$ & $421(1.7)$ & $511(2.0)$ & 0.003 \\
\hline Mechanical ventilation, $n(\%)$ & $3227(12.7)$ & 4034 (12.7) & 0.811 & $3227(12.7)$ & $3044(12)$ & 0.014 \\
\hline Decompressive craniectomy, $n(\%)$ & $1262(5.0)$ & $2052(6.4)$ & $<0.001$ & $1262(5.0)$ & $1578(6.2)$ & $<0.001$ \\
\hline LOHS, median (IQR) & $8(13)$ & $7(12)$ & $<0.001$ & $8(13)$ & $7(12)$ & $<0.001$ \\
\hline In-hospital mortality, $n(\%)$ & $7344(29.0)$ & $7719(24.2)$ & $<0.001$ & $7344(29.0)$ & $6019(23.7)$ & $<0.001$ \\
\hline
\end{tabular}

PSM: propensity score matching. COPD: chronic obstructive pulmonary disease. AIDS acquired immunodeficiency syndrome. LOHS: length of hospital stay. IQR: interquartile range. The $p$-values are for comparisons between men and women.

\subsection{Factors Associated with IHM during Admission for Hemorrhagic Stroke}

According to the type of HS, IHM was highest for nontraumatic intracerebral hemorrhage in both men and women (Table 4). For all types of HS, IHM was higher among women than among men, both before and after PSM. Increments in age and CCI were associated were increased IHM in both sexes, with women showing higher IHM for most categories of these variables. Use of OACs and antiplatelet agents were associated with higher IHM among women than among men.

For most chronic conditions, we detected no significant differences in IHM between men and women, either before or after PSM (Table 5). However, women with diabetes, 
hemiplegia/paraplegia, chronic renal disease and atrial fibrillation did not survive to hospital discharge in a higher proportion than that for men. Decompressive craniectomy was associated with a higher IHM among women than among men both before and after PSM (20.76\% vs. $15.64 \%$ and $20.76 \%$ vs. $14.26 \%$, respectively; both $p$-values $<0.001)$.

Table 4. In-hospital mortality according to type of hemorrhagic stroke, age, Charlson comorbidity index and lifestyle variables before and after propensity score matching (PSM) for men and women hospitalized for hemorrhagic stroke in Spain from 2016 to 2018.

\begin{tabular}{|c|c|c|c|c|c|c|}
\hline \multirow{2}{*}{ Variables } & \multicolumn{3}{|c|}{ IHM Before PSM } & \multicolumn{3}{|c|}{ IHM After PSM } \\
\hline & Women & Men & $p$-Value & Women & Men & $p$-Value \\
\hline $\begin{array}{l}\text { Nontraumatic subarachnoid } \\
\text { hemorrhage, } n(\%)\end{array}$ & $1478(23.2)$ & $986(21.2)$ & 0.017 & $1478(23.2)$ & $912(20.6)$ & 0.002 \\
\hline $\begin{array}{c}\text { Nontraumatic intracerebral } \\
\text { hemorrhage, } n(\%)\end{array}$ & $4598(33.5)$ & $5180(29.2)$ & $<0.001$ & $4598(33.5)$ & $4137(28.9)$ & $<0.001$ \\
\hline $\begin{array}{l}\text { Other and unspecified nontraumatic } \\
\text { intracranial hemorrhage, } n(\%)\end{array}$ & $1268(24.2)$ & $1553(16.4)$ & $<0.001$ & $1268(24.2)$ & $970(14.7)$ & $<0.001$ \\
\hline Age, mean (SD) & $77.55(12.9)$ & $74.00(13.3)$ & $<0.001$ & $77.55(12.9)$ & $75.48(12.6)$ & $<0.001$ \\
\hline $18-54$ years, $n(\%)$ & $544(14.4)$ & $799(15.6)$ & 0.118 & $544(14.4)$ & $490(13.9)$ & 0.576 \\
\hline $55-69$ years, $n(\%)$ & $1029(20.8)$ & $1591(19.3)$ & 0.033 & $1029(20.8)$ & $1147(18.2)$ & 0.001 \\
\hline $70-84$ years, $n(\%)$ & $3280(31.1)$ & $3548(26.3)$ & $<0.001$ & $3280(31.1)$ & $2802(25.3)$ & $<0.001$ \\
\hline$\geq 85$ years, $n(\%)$ & $2491(40.9)$ & $1781(35.6)$ & $<0.001$ & $2491(40.9)$ & $1580(35.3)$ & $<0.001$ \\
\hline CCI, mean (SD) & $0.76(0.7)$ & $1.03(0.9)$ & $<0.001$ & $0.76(0.7)$ & $0.77(0.7)$ & 0.665 \\
\hline $\mathrm{CCI}=0, n(\%)$ & $3484(26.2)$ & $2856(20.1)$ & $<0.001$ & $3484(26.2)$ & $2747(20.4)$ & $<0.001$ \\
\hline $\mathrm{CCI}=1, n(\%)$ & $2539(30.9)$ & $2716(25.0)$ & $<0.001$ & $2539(30.9)$ & $2204(25.6)$ & $<0.001$ \\
\hline $\mathrm{CCI}>1, n(\%)$ & $1321(34.6)$ & $2147(31.5)$ & 0.001 & $1321(34.6)$ & $1068(32.3)$ & 0.038 \\
\hline Obesity, $n(\%)$ & $404(29.3)$ & $367(22.5)$ & $<0.001$ & $404(29.3)$ & $267(23.0)$ & $<0.001$ \\
\hline Hypertension, $n(\%)$ & $3885(29.6)$ & $3976(23.3)$ & $<0.001$ & $3885(29.6)$ & $3098(22.9)$ & $<0.001$ \\
\hline Lipid metabolism disorders, $n(\%)$ & $2123(28.8)$ & $2223(23.5)$ & $<0.001$ & $2123(28.8)$ & $1625(22.9)$ & $<0.001$ \\
\hline Alcohol abuse, $n(\%)$ & $111(27.0)$ & $703(23.7)$ & 0.137 & $111(27.0)$ & $443(22.4)$ & 0.042 \\
\hline Use of oral anticoagulants, $n(\%)$ & $1131(38.27)$ & $1390(31.56)$ & $<0.001$ & $1131(38.27)$ & $1267(36.42)$ & 0.111 \\
\hline Use of antiplatelet agents, $n(\%)$ & $692(34.89)$ & $965(30.10)$ & 0.001 & $692(34.89)$ & 1065 (33.17) & 0201 \\
\hline
\end{tabular}

IHM: in-hospital mortality. PSM: propensity score matching. SD: standard deviation. CCI: Charlson comorbidity index. The $p$-values are for comparisons between men and women.

Table 5. In-hospital mortality (IHM) according to comorbidities, use of therapeutic procedures and length of hospital stay before and after propensity score matching (PSM) for men and women hospitalized for hemorrhagic stroke in Spain from 2016 to 2018.

\begin{tabular}{|c|c|c|c|c|c|c|}
\hline \multirow{2}{*}{ Variables } & \multicolumn{3}{|c|}{ IHM Before PSM } & \multicolumn{3}{|c|}{ IHM After PSM } \\
\hline & Women & Men & $p$-Value & Women & Men & $p$-Value \\
\hline Acute myocardial infarction, $n(\%)$ & $122(38.1)$ & $339(31.2)$ & 0.021 & $122(38.1)$ & $51(35.4)$ & 0.577 \\
\hline Congestive heart failure, $n(\%)$ & $422(41.4)$ & $485(39.2)$ & 0.297 & $422(41.4)$ & $354(38.4)$ & 0.181 \\
\hline Peripheral vascular disease, $n(\%)$ & $113(28.3)$ & $381(31.0)$ & 0.316 & $113(28.3)$ & $80(35.6)$ & 0.061 \\
\hline Dementia, $n(\%)$ & $748(39.0)$ & $497(35.8)$ & 0.054 & $748(39.0)$ & $471(35.8)$ & 0.066 \\
\hline COPD, $n(\%)$ & $406(30.3)$ & $900(29.8)$ & 0.761 & $406(30.3)$ & $387(32.3)$ & 0.277 \\
\hline Rheumatoid disease, $n(\%)$ & $113(27.7)$ & $57(24.6)$ & 0.389 & $113(27.7)$ & $56(24.5)$ & 0.374 \\
\hline Peptic ulcer, $n(\%)$ & $12(21.8)$ & $34(24.6)$ & 0.678 & $12(21.8)$ & $15(30.6)$ & 0.309 \\
\hline Diabetes, $n(\%)$ & $1471(32.9)$ & $1970(26.5)$ & $<0.001$ & $1471(32.9)$ & $1251(25.6)$ & $<0.001$ \\
\hline Hemiplegia/Paraplegia, $n(\%)$ & $1032(25.7)$ & $1255(22.9)$ & 0.002 & $1032(25.7)$ & $930(22.7)$ & 0.001 \\
\hline Chronic renal disease, $n(\%)$ & $599(37.1)$ & $901(34.4)$ & 0.076 & $599(37.1)$ & $537(33.3)$ & 0.025 \\
\hline Chronic liver disease, $n(\%)$ & $273(35.1)$ & $543(32.5)$ & 0.201 & $273(35.1)$ & $257(33.0)$ & 0.382 \\
\hline Cancer, $n(\%)$ & $154(35.0)$ & $399(35.9)$ & 0.753 & $154(35.0)$ & $137(39.8)$ & 0.165 \\
\hline Metastatic cancer, $n(\%)$ & $123(49.0)$ & $193(43.1)$ & 0.131 & $123(49.0)$ & $122(45.4)$ & 0.405 \\
\hline AIDS, $n(\%)$ & $9(42.9)$ & $30(31.9)$ & 0.341 & $9(42.9)$ & $2(40.0)$ & 0.908 \\
\hline Atrial fibrillation, $n(\%)$ & $1821(39.2)$ & $1991(34.8)$ & $<0.001$ & $1821(39.2)$ & $1575(34.8)$ & $<0.001$ \\
\hline Anemia, $n(\%)$ & $204(28.1)$ & $151(24.1)$ & 0.098 & $204(28.1)$ & $129(22.9)$ & 0.035 \\
\hline Depression, $n(\%)$ & $493(25.6)$ & $228(23.8)$ & 0.287 & $493(25.6)$ & $220(23.5)$ & 0.219 \\
\hline Sepsis, $n(\%)$ & $135(53.2)$ & $244(52.8)$ & 0.931 & 135 (53.2) & $180(50.7)$ & 0.552 \\
\hline Nosocomial pneumonia, $n(\%)$ & $134(31.8)$ & $223(32.6)$ & 0.790 & $134(31.8)$ & $159(31.1)$ & 0.815 \\
\hline Mechanical ventilation, $n(\%)$ & $1896(58.8)$ & $2397(59.4)$ & 0.566 & $1896(58.8)$ & $1768(58.1)$ & 0.589 \\
\hline Decompressive craniectomy, $n(\%)$ & $262(20.8)$ & $321(15.6)$ & $<0.001$ & $262(20.8)$ & $225(14.3)$ & $<0.001$ \\
\hline LOHS, median (IQR) & $3(7)$ & $3(7)$ & 0.897 & $3(7)$ & $3(7)$ & 0.766 \\
\hline
\end{tabular}

IHM: in-hospital mortality. PSM: propensity score matching. COPD: chronic obstructive pulmonary disease. AIDS acquired immunodeficiency syndrome. LOHS: length of hospital stay. IQR: interquartile rate. The $p$-values are for comparisons between men and women. 
The results of the multivariable logistic regression analyses are shown in Table 6. For men and women, IHM increased with age, congestive heart failure, dementia, diabetes, sepsis, use of OACs or antiplatelet agents and the need for mechanical ventilation during hospitalization. COPD, kidney disease and peripheral vascular disease predicted IHM only among men.

Table 6. Multivariable logistic regression analysis of factors associated with in-hospital mortality for both women and men hospitalized for hemorrhagic stroke in Spain from 2016 to 2018 and sensitivity analysis combining data from women and men.

\begin{tabular}{cccc}
\hline & Women & Men & Both \\
\hline Variables & OR (95\% CI) & OR (95\% CI) & OR (95\% CI) \\
\hline 18-54 years & 1 & 1 & 1 \\
55-69 years & $1.67(1.48-1.90)$ & $1.38(1.24-1.53)$ & $1.57(1.43-1.72)$ \\
70-84 years & $4.02(3.58-4.53)$ & $2.80(2.53-3.10)$ & $3.45(3.17-3.76)$ \\
$\geq 85$ years & $7.73(6.82-8.76)$ & $5.38(4.80-6.04)$ & $6.72(6.13-7.36)$ \\
Obesity & $0.87(0.82-0.93)$ & $0.88(0.83-0.93)$ & $0.88(0.84-0.92)$ \\
Congestive heart failure & $1.26(1.10-1.45)$ & $1.45(1.27-1.65)$ & $1.33(1.20-1.47)$ \\
Peripheral vascular disease & NS & $1.20(1.05-1.38)$ & NS \\
Dementia & $1.41(1.27-1.56)$ & $1.62(1.44-1.83)$ & $1.51(1.40-1.64)$ \\
COPD & NS & $1.17(1.04-1.41)$ & NS \\
Diabetes & $1.10(1.02-1.19)$ & $1.09(1.02-1.16)$ & $1.06(1.01-1.13)$ \\
Chronic renal disease & NS & $1.34(1.21-1.48)$ & $1.18(1.08-1.29)$ \\
Sepsis & $2.50(1.88-3.32)$ & $2.83(2.28-3.51)$ & $2.58(2.15-3.11)$ \\
Use of oral anticoagulants & $1.64(1.41-186)$ & $1.59(1.30-1.70)$ & $1.62(1.35-1.80)$ \\
Use of antiplatelet agents & $1.36(1.18-1.60)$ & $1.31(1.11-1.52)$ & $1.33(1.15-1.51)$ \\
Mechanical ventilation & $9.63(8.77-10.59)$ & $11.61(10.68-12.63)$ & $10.51(9.82-11.24)$ \\
Decompressive craniectomy & $0.49(0.42-0.58)$ & $0.38(0.33-0.43)$ & $0.41(0.36-0.46)$ \\
Women & NA & NA & $1.23(1.18-1.28)$ \\
\hline
\end{tabular}

OR (95\% CI): odds ratio (95\% confidence interval). COPD: chronic obstructive pulmonary disease. NS: nonsignificant (only variables with significant results in the multivariable regression analysis are shown in the table). NA: not applicable.

Obesity was associated with lower IHM both among women and men (OR $=0.87$, 95\% CI 0.82-0.93 and OR $=0.88,95 \%$ CI 0.83-0.93, respectively). Undergoing decompressive craniectomy was significantly associated with survival at hospital discharge in both sexes $(\mathrm{OR}=0.49,95 \%$ CI $0.42-0.58$ in women and $\mathrm{OR}=0.38,95 \%$ CI $0.33-0.43$ in men).

\subsection{Sensitivity Analysis}

When we joined the databases of women and men for a sensitivity analysis, we confirmed the results of the PSM, finding that women were $23 \%$ significantly more likely to die in the hospital when admitted for HS than men were (OR $=1.23,95 \%$ CI 1.18-1.28) (Table 6).

\section{Discussion}

Here we found that the incidence of HS per 100,000 inhabitants was higher among men than among women. Women more often suffered subarachnoid hemorrhages, whereas men were more often admitted for intracerebral and other unspecified intracranial hemorrhages. Women underwent decompressive craniectomy less often than men even though decompressive craniectomy was associated with increased survival at hospital discharge in both sexes. Obesity was associated with lower IHM both among women and men, and the use of OACs or antiplatelet agents was associated with higher IHM. In the multivariable regression analysis, women were $23 \%$ more likely than men to die in the hospital when admitted for HS.

In our study, the incidence of HS was higher among men than among women. Similar differences have been reported in previous research $[2,17,18]$. Studies including different subtypes of HS generally include more cases of cerebral parenchymal bleeding than those 
with subarachnoid hemorrhage. The latter is more commonly coded in women, but its impact on the overall number of cases of HS is lesser. We detected a higher number of HS in women $\geq 85$ years old than in men of the same age group, but the incidence per 100,000 people was lower. Previous publications have reported higher numbers of HS in very old women; they did not account for the total population in the denominator [19]. Thus, an age interaction effect is unlikely to be proven.

Several factors may help explain the higher incidence of HS in men. At a given age, men have higher blood pressure than women [20], which is a paramount factor for the onset of brain bleeding [21]. It is not known whether gonadal hormones may be playing a role, but different patterns of HS have been described for premenopausal as compared with postmenopausal women [22]. Estrogen treatment results in decreased cell death in neuronal cultures after free radical iron injury and this circumstance is somewhat similar to intracranial bleeding [23].

We confirmed that women underwent decompressive craniectomy less often than men even though decompressive craniectomy was associated with increased survival in both sexes in the multivariable regression analysis. Our group formerly described increasing rates for this procedure during the period 2003-2012 in our country [24]. Most research work in this regard comes from uncontrolled studies, which show modest beneficial effects after craniectomy and evacuation of a hematoma [25]. Its apparent association with a better outcome may be confounded by the indication of the procedure in patients with better functional condition or health status before the stroke, or rather the subjective perception on behalf of the treating clinicians of a better prognosis after the surgery. A randomized controlled trial to determine the actual usefulness of decompressive craniectomy in the management of HS is currently ongoing [26].

Obesity was associated with a lower IHM both among women and men. The design of our study does not allow us to know the answer to what has been called the obesity paradox in stroke [27]. Regrettably, many of the studies that deal with this concept have an observational study design, show inaccuracies in body weight measurement and are susceptible to selection and survival biases too [28].

We agree with many other observational and clinical studies finding increased IHM after HS among those taking OACs and antiplatelet agents prior to hospitalization besides the influence of sex [29-34].

Inohara et al. analyzed data of 141,311 patients with HS and reported that after adjustment for confounders, prior use of warfarin (OR 1.62; 97.5\% CI 1.53-1.71) and prior use of non-vitamin $\mathrm{K}$ antagonist oral anticoagulants (OR, 1.21; 97.5\% CI 1.11-1.32) were associated with increased IHM when compared with those not taking OACs. These associations remained significant when patients using any antiplatelet agents were excluded [29].

Data of 13,291 patients included in the Swedish Stroke Register between 2012 and 2016 showed that OACs (hazard ratio 1.93; 95\% CI, 1.57-2.38) and antiplatelet agents (hazard ratio 1.32; $95 \% \mathrm{CI}, 1.13-1.54)$ were associated with higher risk of mortality in the first $24 \mathrm{~h}[30]$.

A meta-analysis including results of 25 cohort studies concluded that IHM in patients with preceding use of antiplatelet agent was $27 \%$ higher than among those not consuming these drugs (OR 1.27, 95\% CI 1.10-1.47) [31].

The larger baseline hematoma and the increased risk of hematoma expansion are the reasons for the negative effect of OACs and antiplatelet agents on severity and mortality after HS [29-34]. Unfortunately, in the SNHDD, information regarding the initial hematoma volume, degree of hematoma expansion and type, duration or number of OACs and antiplatelet agents used is not available [11,24].

In our multivariable regression analysis, women were more likely than men to die in the hospital when admitted for HS. Again, differences in the design of the studies can offer variable results [35]. If it is true that women have a poorer short-term prognosis after a HS and the differences cannot be explained by a distinct medical management, biology could eventually provide the answer. Inflammation and cell death might occur earlier, as seen 
in animal models of intracranial hemorrhages induced by bacterial collagenases [36]. The mechanical injury of the brain tissue and its direct consequence, brain edema, the potential reparative and anti-inflammatory roles of microglia and macrophages in the later phase of the intracranial hemorrhage to resorb the bleeding and resolve the edema, or the release of thrombin, plasmin and reactive oxygen species that cause brain cell damage following intracranial hemorrhage, might differ between sexes [37-39].

In addition to those mentioned before, several limitations must be considered. First, we lack data on baseline stroke severity, which is an important predictor of outcome and, therefore, an important residual confounder variable [24,40-43]. Second, a selection bias is possible because HS patients having more rapidly fatal and less severe symptoms and those with a worse access to medical care may be underrepresented [40]. Third, in the SNHDD, information on laboratory results is not collected, so the effect of hematological or biochemical disorders cannot be evaluated [11]. Fourth, even if PSM has surely helped to attenuate differences in baseline clinical variables, complete elimination of residual confounding is difficult to achieve in observational studies [40-43]. Fifth, as we used anonymized data, a patient hospitalized two or more times with HS would be considered as different individuals [11]. Sixth, we excluded from the study population patients with a code for history of previous stroke. Therefore, this condition was not analyzed as a factor associated with IHM. Seventh, the quality of coding may be affected by poor charting by physicians, lack of time to "code everything", lack of perceived importance by health coders or when codes that lead to greater reimbursement of funds to hospitals are favored over the principal reason for which a patient is hospitalized $[24,40,41,43]$. Eighth, mortality once patients are discharged from the hospital is not available [11]. Ninth, stratifying patients according to the intracerebral hemorrhage (ICH) score as well as the Hunt-Hess grade for subarachnoid hemorrhage (SAH) would have improved the results of our investigation [44,45]. Unfortunately, the SNHDD does not include data on the $\mathrm{ICH}$ volume or the Glasgow Coma Scale coma severity score necessary to calculate the ICH score. Furthermore, detailed symptomatology, such as severity of headache or neck stiffness, among others, that are used to estimate the Hunt-Hess grade for SAH are also lacking in the SNHDD.

However, the strengths of administrative databases such as the SNHDD, include that (1) they reflect real-world practice at a national level; (2) they are large, so infrequent diseases or risk factors associated with stroke can also be evaluated; (3) they are a cost-effective alternative for monitoring stroke incidence and burden; (4) the validity of ICD codes to investigate HS in administrative databases has been demonstrated in Spain and other countries suggesting that when these data are applied to an appropriate question with validated case definitions, high-quality and reliable conclusions can be inferred [40-43,46-50]. In a representative sample of 30 Spanish hospitals, when compared with medical records, the ICD-9 codes for HS as a primary diagnosis registered in the SNHDD were correct in 43 of 49 cases reviewed $(87.75 \%)$ [50].

In our opinion, the strengths of this study and its uniqueness clearly outweigh its limitations. Furthermore, the SNHDD, like hospital discharge administrative databases from other countries, has already been used to assess trends, demographic and clinical characteristics and outcomes of hospitalizations with stroke [24,51-57].

In any case, our study is the starting point for future investigations that should confirm or discard our conclusions using larger and more precise clinical data.

\section{Conclusions}

In conclusion, women were more likely than men to die in the hospital when admitted for HS even accounting for confounding factors through a matched-pair analysis. Although biological differences are a possibility, especially after menopause, the scientific community should be concerned about plausible disparities in the clinical management based on patients' sex, such as a lesser use of potentially lifesaving procedures. 
Supplementary Materials: The following are available online at https:/ / www.mdpi.com/article/10 $.3390 /$ jcm10163753/s1, Table S1: International Classification of Disease, 10th edition, (ICD-10) codes for the clinical diagnoses and procedures used in this investigation.

Author Contributions: Conceptualization, J.M.d.M.-Y., M.L.-H. and R.J.-G.; data curation, V.H.-B., D.C.-A., J.d.M.-D. and M.M.-B.; formal analysis, V.H.-B. and N.P.-F.; methodology, A.L.-d.-A., R.J.-G. and N.M.-R.; writing—original draft preparation, J.M.d.M.-Y., M.L.-H. and R.J.-G.; writing—review and editing, A.L.-d.-A., D.C.-A., J.d.M.-D., M.M.-B., N.P.-F. and N.M.-R. All authors have read and agreed to the published version of the manuscript.

Funding: This research received no external funding.

Institutional Review Board Statement: Not applicable.

Informed Consent Statement: Not applicable.

Data Availability Statement: According to the contract signed with the Spanish Ministry of Health and Social Services, which provided access to the databases from the Spanish National Hospital Database (Conjunto Mínimo Basico de Datos; CMBD), we cannot share the databases with any other investigator, and we have to destroy the databases once the investigation has concluded. Consequently, we cannot upload the databases to any public repository. However, any investigator can apply for access to the databases by filling out the questionnaire available at http:/ / www.msssi.gob.es/estadEstudios/estadisticas/estadisticas / estMinisterio/SolicitudCMBDdocs/Formulario_Peticion_Datos_CMBD.pdf. All other relevant data are included in the paper.

Conflicts of Interest: The authors declare no conflict of interest.

\section{References}

1. Van Asch, C.J.; Luitse, M.J.; Rinkel, G.J.; van der Tweel, I.; Algra, A.; Klijn, C.J. Incidence, case fatality, and functional outcome of intracerebral haemorrhage over time, according to age, sex, and ethnic origin: A systematic review and meta-analysis. Lancet Neurol. 2010, 9, 167-176. [CrossRef]

2. Rincon, F.; Mayer, S.A. The epidemiology of intracerebral hemorrhage in the United States from 1979 to 2008. Neurocrit. Care 2013, 19, 95-102. [CrossRef] [PubMed]

3. Carlsson, M.; Wilsgaard, T.; Johnsen, S.H.; Vangen-Lønne, A.M.; Løchen, M.L.; Njølstad, I.; Mathiesen, E.B. Temporal trends in incidence and case fatality of intracerebral hemorrhage: The Tromsø Study 1995-2012. Cerebrovasc. Dis. Extra 2016, 6, 40-49. [CrossRef]

4. Krishnamurthi, R.V.; Moran, A.E.; Forouzanfar, M.H.; Bennett, D.A.; Mensah, G.A.; Lawes, C.M.; Barker-Collo, S.; Connor, M.; Roth, G.A.; Sacco, R.; et al. The global burden of hemorrhagic stroke: A summary of findings from the GBD 2010 study. Glob. Heart 2014, 9, 10106. [CrossRef] [PubMed]

5. Nilsson, O.G.; Lindgren, A.; Ståhl, N.; Brandt, L.; Säveland, H. Incidence of intracerebral and subarachnoid haemorrhage in southern Sweden. J. Neurol. Neurosurg. Psychiatry 2000, 69, 601-607. [CrossRef] [PubMed]

6. Wagner, I.; Volbers, B.; Kloska, S.; Doerfler, A.; Schwab, S.; Staykov, D. Sex differences in perihemorrhagic edema evolution after spontaneous intracerebral hemorrhage. Eur. J. Neurol. 2012, 19, 1477-1481. [CrossRef] [PubMed]

7. Anderson, C.S.; Huang, Y.; Wang, J.G.; Arima, H.; Neal, B.; Peng, B.; Heeley, E.; Skulina, C.; Parsons, M.W.; Kim, J.S.; et al. Intensive blood pressure reduction in acute cerebral haemorrhage trial (INTERACT): A randomised pilot trial. Lancet Neurol. 2008, 7, 391-399. [CrossRef]

8. Gokhale, S.; Caplan, L.R.; James, M.L. Sex differences in incidence, pathophysiology, and outcome of primary intracerebral hemorrhage. Stroke 2015, 46, 886-892. [CrossRef]

9. Roquer, J.; Rodríguez-Campello, A.; Jiménez-Conde, J.; Cuadrado-Godia, E.; Giralt-Steinhauer, E.; Vivanco Hidalgo, R.M.; Soriano, C.; Ois, A. Sex-related differences in primary intracerebral hemorrhage. Neurology 2016, 87, 257-262. [CrossRef]

10. Rubin, D.B. Matching to Remove Bias in Observational Studies. Biometrics 1973, 29, 159. [CrossRef]

11. Ministerio de Sanidad, Servicios Sociales e Igualdad. Real Decreto 69/2015, de 6 de Febrero, Por el Que se Regula el Registro de Actividad de Atención Sanitaria Especializada. BOE 2015, 35, 10789-10809. Available online: https:/ /www.mscbs.gob.es/ estadEstudios/estadisticas/docs/BOE_RD_69_2015_RAE_CMBD.pdf (accessed on 12 November 2020).

12. De Miguel-Yanes, J.M.; Jiménez-García, R.; Hernandez-Barrera, V.; de Miguel-Díez, J.; Muñoz-Rivas, N.; Méndez-Bailón, M.; Pérez-Farinós, N.; López-Herranz, M.; Lopez-de-Andres, A. Sex Differences in the Incidence and Outcomes of Acute Myocardial Infarction in Spain, 2016-2018: A Matched-Pair Analysis. J. Clin. Med. 2021, 10, 1795. [CrossRef] [PubMed]

13. Spanish National Statistics Institute. Instituto Nacional de Estadistica, INE Populations by Year, Sex and Age Group. Available online: https: / /www.ine.es/jaxi/Tabla.htm?path=/t20/e245/p08/10/\&file=03003.px\&L=0 (accessed on 6 April 2021).

14. Sundararajan, V.; Henderson, T.; Perry, C.; Muggivan, A.; Quan, H.; Ghali, W.A. New ICD-10 version of the Charlson comorbidity index predicted in-hospital mortality. J. Clin. Epidemiol. 2004, 57, 1288-1294. [CrossRef] [PubMed] 
15. De Miguel-Yanes, J.M.; Jiménez-García, R.; Hernández-Barrera, V.; de Miguel-Díez, J.; Méndez-Bailón, M.; Muñoz-Rivas, N.; Pérez-Farinós, N.; López-de-Andrés, A. Infective endocarditis according to type 2 diabetes mellitus status: An observational study in Spain, 2001-2015. Cardiovasc. Diabetol. 2019, 18, 161. [CrossRef] [PubMed]

16. Ministerio de Sanidad, Consumo y Bienestar Social. Solicitud de Extracción de Datos-Extraction Request (Spanish National Hospital Discharge Database). Available online: https:/ /www.mscbs.gob.es/estadEstudios/estadisticas/estadisticas/estMinisterio/ SolicitudCMBDdocs/2018_Formulario_Peticion_Datos_RAE_CMBD.pdf (accessed on 12 November 2020).

17. Appelros, P.; Stegmayr, B.; Terént, A. Sex differences in stroke epidemiology: A systematic review. Stroke 2009, 40, 1082-1090. [CrossRef]

18. Petrea, R.E.; Beiser, A.S.; Seshadri, S.; Kelly-Hayes, M.; Kase, C.S.; Wolf, P.A. Gender differences in stroke incidence and poststroke disability in the Framingham heart study. Stroke 2009, 40, 1032-1037. [CrossRef]

19. Hsieh, J.T.; Ang, B.T.; Ng, Y.P.; Allen, J.C.; King, N.K.K. Comparison of gender differences in intracerebral hemorrhage in a multi-ethnic Asian population. PLoS ONE 2016, 11, e0152945. [CrossRef]

20. Khoury, S.; Yarows, S.A.; O'Brien, T.K.; Sowers, J.R. Ambulatory blood pressure monitoring in a nonacademic setting: Effects of age and sex. Am. J. Hypertens. 1992, 5, 616-623. [CrossRef] [PubMed]

21. O'Donnell, M.J.; Xavier, D.; Liu, L.; Zhang, H.; Chin, S.L.; Rao-Melacini, P.; Rangarajan, S.; Islam, S.; Pais, P.; McQueen, M.J.; et al. Risk factors for ischaemic and intracerebral haemorrhagic stroke in 22 countries (the INTERSTROKE study): A case-control study. Lancet 2010, 376, 112-123. [CrossRef]

22. Feldmann, E.; Broderick, J.P.; Kernan, W.N.; Viscoli, C.M.; Brass, L.M.; Brott, T.; Morgenstern, L.B.; Wilterdink, J.L.; Horwitz, R.I. Major risk factors for intracerebral hemorrhage in the young are modifiable. Stroke 2005, 36, 1881-1885. [CrossRef]

23. Regan, R.F.; Guo, Y. Estrogens attenuate neuronal injury due to hemoglobin, chemical hypoxia, and excitatory amino acids in murine cortical cultures. Brain Res. 1997, 764, 133-140. [CrossRef]

24. Muñoz-Rivas, N.; Méndez-Bailón, M.; Hernández-Barrera, V.; de Miguel-Yanes, J.M.; Jiménez-García, R.; Esteban-Hernández, J.; López-de-Andrés, A. Type 2 diabetes and hemorrhagic stroke: A population-based study in Spain from 2003 to 2012 . J. Stroke Cerebrovasc. Dis. 2016, 25, 1431-1443. [CrossRef] [PubMed]

25. Takeuchi, S.; Wada, K.; Nagatani, K.; Otani, N.; Mori, K. Decompressive hemicraniectomy for spontaneous intracerebral hemorrhage. Neurosurg. Focus 2013, 34, E5. [CrossRef] [PubMed]

26. Decompressive Hemicraniectomy in Intracerebral Hemorrhage (SWITCH). Clinical Trial. Available online: https://www. clinicaltrials.gov / ct2/show / NCT02258919 (accessed on 16 May 2021).

27. Hoffman, H.; Jalal, M.S.; Furst, T.; Chin, L.S. The obesity paradox in spontaneous intracerebral hemorrhage: Results from a retrospective analysis of the nationwide inpatient sample. Neurocrit. Care 2020, 32, 765-774. [CrossRef] [PubMed]

28. Oesch, L.; Tatlisumak, T.; Arnold, M.; Sarikaya, H. Obesity paradox in stroke. Myth or reality? A systematic review. PLoS ONE 2017, 12, e0171334. [CrossRef]

29. Inohara, T.; Xian, Y.; Liang, L.; Matsouaka, R.A.; Saver, J.L.; Smith, E.E.; Schwamm, L.H.; Reeves, M.J.; Hernandez, A.F.; Bhatt, D.L.; et al. Association of Intracerebral Hemorrhage Among Patients Taking Non-Vitamin K Antagonist vs Vitamin K Antagonist Oral Anticoagulants With In-Hospital Mortality. JAMA 2018, 319, 463-473. [CrossRef]

30. Apostolaki-Hansson, T.; Ullberg, T.; Pihlsgård, M.; Norrving, B.; Petersson, J. Prognosis of Intracerebral Hemorrhage Related to Antithrombotic Use: An Observational Study From the Swedish Stroke Register (Riksstroke). Stroke 2021, 52, 966-974. [CrossRef]

31. Thompson, B.B.; Béjot, Y.; Caso, V.; Castillo, J.; Christensen, H.; Flaherty, M.L.; Foerch, C.; Ghandehari, K.; Giroud, M.; Greenberg, S.M.; et al. Prior antiplatelet therapy and outcome following intracerebral hemorrhage: A systematic review. Neurology 2010, 75, 1333-1342. [CrossRef]

32. Xian, Y.; Zhang, S.; Inohara, T.; Grau-Sepulveda, M.; Matsouaka, R.A.; Peterson, E.D.; Piccini, J.P.; Smith, E.E.; Sheth, K.N.; Bhatt, D.L.; et al. Clinical Characteristics and Outcomes Associated With Oral Anticoagulant Use Among Patients Hospitalized With Intracerebral Hemorrhage. JAMA Netw. Open 2021, 4, e2037438. [CrossRef]

33. Franco, L.; Paciaroni, M.; Enrico, M.L.; Scoditti, U.; Guideri, F.; Chiti, A.; De Vito, A.; Terruso, V.; Consoli, D.; Vanni, S.; et al. Mortality in patients with intracerebral hemorrhage associated with antiplatelet agents, oral anticoagulants or no antithrombotic therapy. Eur. J. Intern. Med. 2020, 75, 35-43. [CrossRef]

34. Law, Z.K.; Desborough, M.; Roberts, I.; Al-Shahi Salman, R.; England, T.J.; Werring, D.J.; Robinson, T.; Krishnan, K.; Dineen, R.; Laska, A.C.; et al. Outcomes in Antiplatelet-Associated Intracerebral Hemorrhage in the TICH-2 Randomized Controlled Trial. J Am. Heart Assoc. 2021, 10, e019130. [CrossRef]

35. Sandset, E.C.; Wang, X.; Carcel, C.; Sato, S.; Delcourt, C.; Arima, H.; Stapf, C.; Robinson, T.; Lavados, P.; Chalmers, J.; et al. Sex differences in treatment, radiological features and outcome after intracerebral haemorrhage: Pooled analysis of intensive blood pressure reduction in acute cerebral haemorrhage trials 1 and 2. Eur. Stroke J. 2020, 5, 345-350. [CrossRef]

36. Rosenberg, G.A.; Mun-Bryce, S.; Wesley, M.; Kornfeld, M. Collagenase-induced intracerebral hemorrhage in rats. Stroke 1990, 21, 801-807. [CrossRef]

37. Baron, J.C. Mapping the ischaemic penumbra with PET: Implications for acute stroke treatment. Cerebrovasc. Dis. 1999, 9, 193-201. [CrossRef]

38. Tschoe, C.; Bushnell, C.D.; Duncan, P.W.; Alexander-Miller, M.A.; Wolfe, S.Q. Neuroinflammation after intracerebral hemorrhage and potential therapeutic targets. J. Stroke 2020, 22, 29-46. [CrossRef] 
39. Chang, C.-F.; Massey, J.; Osherov, A.; Angenendt da Costa, L.H.; Sansing, L.H. Bexarotene enhances macrophage erythrophagocytosis and hematoma clearance in experimental intracerebral hemorrhage. Stroke 2020, 51, 612-618. [CrossRef]

40. Yu, A.Y.; Holodinsky, J.K.; Zerna, C.; Svenson, L.W.; Jetté, N.; Quan, H.; Hill, M.D. Use and Utility of Administrative Health Data for Stroke Research and Surveillance. Stroke 2016, 47, 1946-1952. [CrossRef] [PubMed]

41. Ung, D.; Kim, J.; Thrift, A.G.; Cadilhac, D.A.; Andrew, N.E.; Sundararajan, V.; Kapral, M.K.; Reeves, M.; Kilkenny, M.F. Promising Use of Big Data to Increase the Efficiency and Comprehensiveness of Stroke Outcomes Research. Stroke 2019, 50, 1302-1309. [CrossRef] [PubMed]

42. McCormick, N.; Bhole, V.; Lacaille, D.; Avina-Zubieta, J.A. Validity of diagnostic codes for acute stroke in administrative databases: A systematic review. PLoS ONE 2015, 10, e0135834. [CrossRef] [PubMed]

43. Kokotailo, R.A.; Hill, M.D. Coding of stroke and stroke risk factors using international classification of diseases, revisions 9 and 10. Stroke 2005, 36, 1776-1781. [CrossRef]

44. Hemphill, J.C., 3rd; Bonovich, D.C.; Besmertis, L.; Manley, G.T.; Johnston, S.C. The ICH score: A simple, reliable grading scale for intracerebral hemorrhage. Stroke 2001, 32, 891-897. [CrossRef] [PubMed]

45. Hunt, W.E.; Hess, R.M. Surgical risk as related to time of intervention in the repair of intracranial aneurysms. J. Neurosurg. 1968, 28, 14-20. [CrossRef] [PubMed]

46. Sedova, P.; Brown, R.D., Jr.; Zvolsky, M.; Kadlecova, P.; Bryndziar, T.; Volny, O.; Weiss, V.; Bednarik, J.; Mikulik, R. Validation of stroke diagnosis in the national registry of hospitalized patients in the Czech Republic. J. Stroke Cerebrovasc. Dis. 2015, 24, 2032-2038. [CrossRef]

47. Park, T.H.; Choi, J.C. Validation of stroke and thrombolytic therapy in Korean National Health Insurance claim data. J. Clin. Neurol. 2016, 12, 42-48. [CrossRef]

48. Hald, S.M.; Kring Sloth, C.; Hey, S.M.; Madsen, C.; Nguyen, N.; García Rodríguez, L.A.; Al-Shahi Salman, R.; Möller, S.; Poulsen, F.R.; Pottegård, A.; et al. Intracerebral hemorrhage: Positive predictive value of diagnosis codes in two nationwide Danish registries. Clin. Epidemiol. 2018, 10, 941-948. [CrossRef]

49. Ryan, O.F.; Riley, M.; Cadilhac, D.A.; Andrew, N.E.; Breen, S.; Paice, K.; Shehata, S.; Sundararajan, V.; Lannin, N.A.; Kim, J.; et al. Factors associated with stroke coding quality: A comparison of registry and administrative data. J. Stroke Cerebrovasc. Dis. 2021, 30, 105469. [CrossRef]

50. Medrano, I.H.; Guillán, M.; Masjuan, J.; Alonso Cánovas, A.; Gogorcena, M.A. Reliability of the minimum basic dataset for diagnoses of cerebrovascular disease. Neurologia 2017, 32, 74-80. [CrossRef]

51. Khan, S.U.; Khan, M.Z.; Khan, M.U.; Khan, M.S.; Mamas, M.A.; Rashid, M.; Blankstein, R.; Virani, S.S.; Johansen, M.C.; Shapiro, M.D.; et al. Clinical and Economic Burden of Stroke Among Young, Midlife, and Older Adults in the United States, $2002-2017$. Mayo Clin. Proc. Innov. Qual. Outcomes 2021, 5, 431-441. [CrossRef]

52. George, M.G.; Tong, X.; Bowman, B.A. Prevalence of Cardiovascular Risk Factors and Strokes in Younger Adults. JAMA Neurol. 2017, 74, 695-703. [CrossRef]

53. Tong, X.; George, M.G.; Gillespie, C.; Merritt, R. Trends in hospitalizations and cost associated with stroke by age, United States 2003-2012. Int. J. Stroke 2016, 11, 874-881. [CrossRef]

54. Eyding, J.; Bartig, D.; Weber, R.; Katsanos, A.H.; Weimar, C.; Hacke, W.; Krogias, C. Inpatient TIA and stroke care in adult patients in Germany-retrospective analysis of nationwide administrative data sets of 2011 to 2017. Neurol. Res. Pract. 2019, 1, 39. [CrossRef]

55. Hyeraci, G.; Spini, A.; Roberto, G.; Gini, R.; Bartolini, C.; Lucenteforte, E.; Corrao, G.; Rea, F. A Systematic Review of CaseIdentification Algorithms Based on Italian Healthcare Administrative Databases for Three Relevant Diseases of the Cardiovascular System: Acute Myocardial Infarction, Ischemic Heart Disease, and Stroke. Epidemiol. Prev. 2019, 43, 37-50. [CrossRef]

56. Lecoffre, C.; de Peretti, C.; Gabet, A.; Grimaud, O.; Woimant, F.; Giroud, M.; Béjot, Y.; Olié, V. National Trends in Patients Hospitalized for Stroke and Stroke Mortality in France, 2008 to 2014. Stroke 2017, 48, 2939-2945. [CrossRef]

57. Roussot, A.; Cottenet, J.; Gadreau, M.; Giroud, M.; Béjot, Y.; Quantin, C. The use of national administrative data to describe the spatial distribution of in-hospital mortality following stroke in France, 2008-2011. Int. J. Health Geogr. 2016, 15, 2. [CrossRef] [PubMed] 